\title{
Statistical study of the substorm onset: its dependence on solar wind parameters and solar illumination
}

\author{
H. Wang ${ }^{1,2}$, H. Lühr ${ }^{1}$, S. Y. Ma ${ }^{2}$, and P. Ritter ${ }^{1}$ \\ ${ }^{1}$ GeoforschungsZentrum, Potsdam, Germany \\ ${ }^{2}$ Dept.of Space Physics, College of Electronic Information, Wuhan University, P. R. China
}

Received: 21 January 2005 - Revised: 31 May 2005 - Accepted: 8 June 2005 - Published: 15 September 2005

\begin{abstract}
Based on 1829 well-defined substorm onsets in the Northern Hemisphere, observed during a 2-year period by the FUV Imager on board the IMAGE spacecraft, a statistical study is performed. From the combination of solar wind parameter observations by ACE and magnetic field observations by the low altitude satellite CHAMP, the location of auroral breakups in response to solar illumination and solar coupling parameters are studied. Furthermore, the correspondence of the onset location with prominent large-scale field-aligned currents and electrojets are investigated. Solar illumination and the related ionospheric conductivity have significant effects on the most probable substorm onset latitude and local time. In sunlight, substorm onsets tend to occur $1 \mathrm{~h}$ earlier in local time and $1.5^{\circ}$ more poleward than in darkness. The solar wind input, represented by the merging electric field, integrated over $1 \mathrm{~h}$ prior to the substorm, correlates well with the latitude of the breakup. Most poleward latitudes of the onsets are found to range around $73^{\circ} \mathrm{mag}$ netic latitude during very quiet times. Field-aligned and Hall currents observed concurrently with the onset are consistent with the signature of a westward travelling surge evolving out of the Harang discontinuity. The observations suggest that the ionospheric conductivity has an influence on the location of the precipitating energetic electron which causes the auroral break-up signature.
\end{abstract}

Keywords. Ionosphere (Auroral ionosphere) - Magnetospheric Physics (Current systems; Magnetosphereionosphere interactions)

\section{Introduction}

A magnetospheric substorm is a complicated phenomenon that is not yet fully understood. An early description of substorms was given by Akasofu (1964). It is usually characterized by four phases: growth, onset, expansion, and recovery.

Correspondence to: $\mathrm{H}$. Wang

(huiwang@gfz-potsdam.de)
During the growth phase the polar cap gradually expands and quiet auroral arcs drift equatorward. At the onset phase, which is also called the auroral breakup, a sudden brightening of the arcs takes place in the late evening sector and at the most equatorward boundary of the discrete arc system. During the expansion phase, the brightened arc evolves explosively into a large-scale disturbance, followed by a poleward expansion of the region of auroral emission. During the recovery phase the auroral intensity slowly returns to the pre-substorm level.

Substorm onset indicates the impulsive unloading of energy previously stored in the magnetospheric tail, which leads to the precipitation of auroral particles (e.g. Rostoker et al., 1987; Baker et al., 1996). The magnetic latitude of onsets is the footprint of the corresponding magnetotail region.

There are many models which propose different source locations in the magnetotail. For example, in the cross-tail current instability model (CCI), the onset location occurs near the Earth $\left(<8 R_{E}\right)$ (Lui, 1996). He claims that plasma instabilities cause a cross-tail current disruption and a divergence into the ionosphere via field-aligned currents (that means, substorm current wedge (SCW)), and reconnection may cause the creation of a plasmoid. Alternative to that, the near-Earth neutral line model (NENL) predicts that the substorm is initiated at a further distance $\left(>20 R_{E}\right)$ where reconnection takes place (Baker et al., 1996). The auroral breakup occurs later than in the CCI model. Based on Geotail measurements, Nagai et al. (1998) confirmed that magnetic reconnection plays an important role in triggering substorms, and they found that the statistical location of NENL should be in the pre-midnight sector of the magnetotail between 20 and $30 R_{E}$. The NENL model has been developed further by Shiokawa et al. (1998), who explained how the braking of the fast earthward burst bulge flows could cause the SCW, and they could explain the current disruption and the more distant region of fast ion flows. The CCI and NENL model can be distinguished by comparing the time when the onsets are observed at some distance in the tail with the time when the substorm events are seen on ground. If the onset is 
observed first at some distance in the tail, the NENL model is more appropriate (Liou et al., 2002).

The correlation of onset characteristics with solar wind parameters provides useful restrictions on the conditions leading to the initiation of a substorm. It is widely accepted that the energy input from the solar wind is transferred to the magnetosphere through the magnetic reconnection process and subsequently released with the substorm onset (e.g. Baker et al., 1996). The substorm onset often follows a northward turning of the IMF (Lyons, 1996). In the literature, the onset characteristics have been studied in comparison with various solar wind parameters. Liou et al. (2001) found that IMF $B_{z}$ had a good correlation and IMF $B_{x}$ had a poor correlation with the magnetic latitude (MLAT) of the substorm, based on 10 months of POLAR UVI observations. Gérard et al. (2004) found that the magnetic latitudes of the onsets were correlated best with the solar wind dynamic pressure. They found that as the solar wind dynamic pressure increased, the onset moved more equatorward. The magnetic local time (MLT) of the onset, on the other hand, showed no dependence on the solar wind parameters. This statement was based on a small subset (78) of substorm events observed in winter.

It is well-known that an increased ionospheric conductivity decreases the likelihood of establishing energetic fieldaligned electrons (which are needed to excite discrete auroras) (Newell et al., 1996). Therefore, it is quite possible that ionospheric conductivity plays a role in the substorm process since it can control the auroral activity. Liou et al. (2001) found that the substorm onsets tended to start at earlier local times in the Northern Hemispheric summer than in winter, and at intermediate local times in spring. Unfortunately, they did not cover the fall season.

The onset location was found to be collocated well with the Harang discontinuity (HD) (Liou et al., 2001). The Harang discontinuity is a region where the convection electric field changes direction from equatorward on the poleward side of the oval to poleward on the equatorward side of the oval. An eastward electrojet is located equatorward and a westward electrojet poleward of the HD with a strong upward field-aligned current at the center of the HD (Koskinen and Pulkkinen, 1995). The onset location was reported to occur at a fixed distance to the equatorward boundary of the aurora (Gérard et al., 2004). This means, as the auroral oval expands with the increasing amount of energy transferred to the magnetosphere, subsequent onsets will also occur at lower latitudes. Therefore, it is expected that the latitude of the associated large-scale field-aligned currents and horizontal ionospheric currents are also well correlated with the location of the substorm onset. The spatial characteristics of the substorm current system is an important topic in substorm studies. Based on FAST particle and magnetometer measurements and IMAGE-FUV observations during one moderate substorm, Mende et al. (2003) found that the location of "inverted $V$ " precipitation and the auroral region are well correlated with upward FACs at substorm onset.
One of the questions we want to address here concerns what effects the ionospheric conductivity and solar coupling parameters may have on the substorm onset, and how they are related to the large-scale FACs and ionospheric current systems. The substorm onset is known as a transient and localized phenomenon. Sparsely distributed all-sky cameras and low temporal resolution spaceborne imagers cannot easily identify the details. However, the systematic detection of the substorm onset by global imagers provides better indications of the initial phase leading to the development of a substorm (Liou et al., 1999). Combining ACE, IMAGE and CHAMP satellite measurements we have studied statistically the possible correlation between the solar coupling parameters, field-aligned and ionospheric horizontal currents and the optical substorm onset characteristics in the auroral region.

In the following section we describe the data set used in this work. In Sect. 3 we studied the seasonal and solar wind effects on the onset locations in terms of magnetic local time and latitude. Subsequently, a statistical analysis of the relation between the latitude of the currents and the substorm onset locations is presented. A discussion of the results and comparison with earlier findings is given in Sect. 4. Section 5 summarizes the main conclusions.

\section{Data set}

The IMAGE satellite is in a highly eccentric polar orbit of $1000 \times 45600 \mathrm{~km}$ altitude. The far ultraviolet (FUV) instrument on board the IMAGE spacecraft provides observations of the northern aurora in ultraviolet light on a global scale with a spatial resolution of $50 \mathrm{~km}$ and a temporal resolution of $\sim 2 \mathrm{~min}$. The prime data source used by Frey et al. (2004) to retrieve the information of substorm onset was a Wideband Imaging Camera (WIC), and if absent, the oxygen imaging Spectrographic Imager channel (SI-13). No other substorm indicators were used. The WIC has a passband at wavelengths of $140-180 \mathrm{~nm}$, which is sensitive to emissions from the $\mathrm{N}_{2} \mathrm{LBH}$-band and atomic NI lines (149.3 nm). The SI-13 has a passband of $5 \mathrm{~nm}$ centered around the $135.6 \mathrm{~nm}$ OI doublet. A detailed description of the instrument on board the IMAGE spacecraft and how to determine auroral substorm onsets from the FUV instrument can be found in Frey et al. (2004).

The following schemes are used for substorm onset identification. To start with, a clear local brightening of the aurora has to occur. Secondly, the aurora has to expand to the poleward boundary of the auroral oval and spread azimuthally in local time for at least $20 \mathrm{~min}$. Finally, a substorm onset is only accepted if at least $30 \mathrm{~min}$ have passed after the previous onset (Frey et al., 2004). Figure 1 shows two auroral images from IMAGE FUV-WIC in the frame of magnetic latitude (MLAT) and local time (MLT) coordinates (the figure was obtained from H. U. Frey). The coordinate frame used to order FUV observations is the Apex coordinate system described by Richmond (1995). A prominent auroral activity at local midnight occurs at 11:20 UT on 2 September 2001. In 

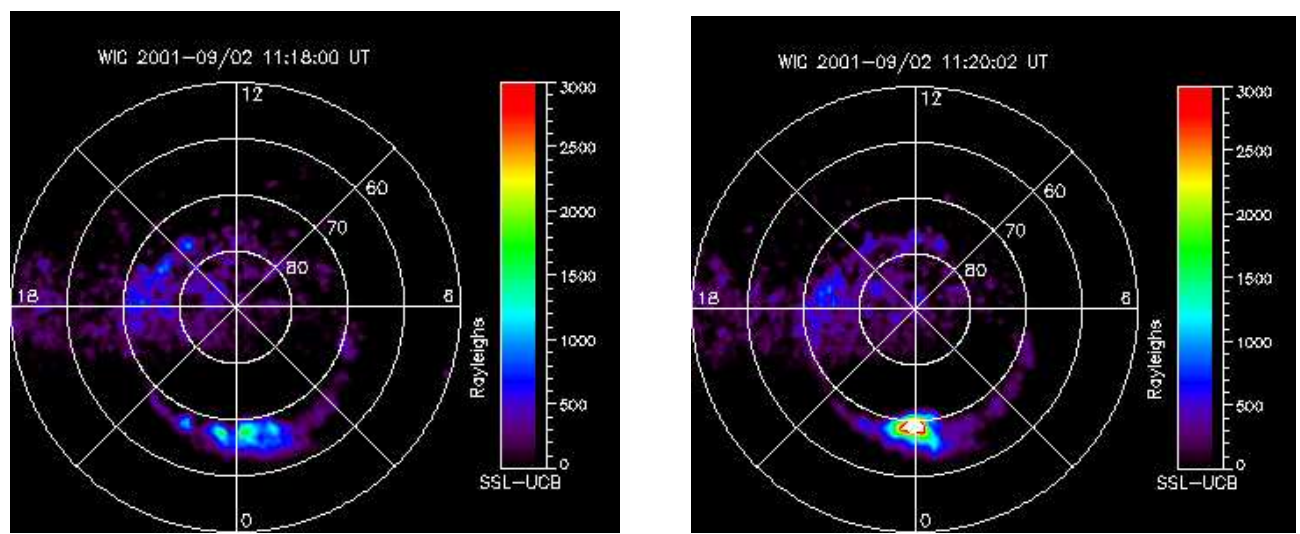

Fig. 1. Auroral images from IMAGE FUV-WIC in the frame of MLAT and MLT coordinates showing one substorm onset event occurring at 11:20:02 UT on 2 September 2001 (provided by H. U. Frey).

the next tens of minutes (not shown here) the aurora expands poleward and azimuthally, which are typical substorm features. The substorm onset times and locations, observed by the IMAGE-FUV for the northern auroral oval covering May 2000 (start of the regular IMAGE-FUV operations) through December 2002, were made available as a supplement to the paper by Frey et al. (2004). The compiled list of substorm onsets times and locations from the first 2.5 years of operation obtained by the WIC instrument covers all seasons. The data of more than 2400 substorm onsets confirm previous findings (Liou et al., 2001) of average distributions in geomagnetic latitude and local time. The median onset location was found at 23:00 MLT and 66.4 MLAT (Frey et al., 2004). The data set is not biased toward any specific geomagnetic longitude, as is expected for long-term observations from a satellite having an orbital period that is not a multiple of the Earth's rotational period.

Although there are no observations of IMAGE in the Southern Hemisphere, we have simply assumed that substorm onsets occur at the same times and conjugated locations in both hemispheres. Therefore, IMAGE FUV observations from the Northern Hemisphere may also provide information for the Southern Hemisphere.

The geoscientific satellite CHAMP was launched on 15 July 2000 into a near-polar $\left(83.7^{\circ}\right.$ inclination) orbit with an initial altitude of around $450 \mathrm{~km}$ (Reigber et al., 2002). Observations of the CHAMP satellite were used to estimate the ionospheric currents in the vicinity of the onset. The satellite carries among others a high-precision Fluxgate vector Magnetometer (FGM) and a scalar Overhauser Magnetometer (OVM) primarily for calibration purposes. Fieldaligned currents are determined according to Ampere's law from the vector field data. It is assumed that the FACs are organized in infinite sheets which are aligned with the mean location of the auroral oval. Further details of the FAC calculations can be found in Wang et al. (2005). The ionospheric Hall currents, here the source free current components, are determined from the scalar magnetic field measurements.
The Hall current is approximated by a series of infinite line currents, and current density is obtained by an inversion method. The positive amplitude marks the eastward (westward) directed current for the descending (ascending) part of the orbit (for details see, Ritter et al., 2004). The results of the current estimates are also ordered in the frame of corrected magnetic coordinates and magnetic local times, which are both calculated from the Apex algorithms described by Richmond (1995). By chance, there are 49 close CHAMP approaches to the onset region during 2001 and 2002. The "close approach" requires that CHAMP passes the location of the substorm onset within a zonal segment of $\pm 15^{\circ}$ in longitude and a time window of $\pm 6 \mathrm{~min}$ of the reported break up time. A distance of about $\pm 60 \mathrm{~km}$ in the east/west direction from the reported onset location can be regarded as acceptable, since the associated currents are organized primarily along the oval.

We use a 1-min interplanetary magnetic field (IMF) and solar wind velocity data collected by the Advanced Composition Explorer (ACE) satellite. The satellite is located at the Lagrange Points (L1) approx. $220 R_{E}\left(\approx 1.48 \times 10^{6} \mathrm{~km}\right)$ in front of the Earth. The transit time to the magnetopause of each substorm event was computed individually using the actual solar wind speed data (the propagation has been done by the standard procedure described on the web page:http://nssdc.gsfc.nasa.gov/omniweb/html/ omni2_doc.html $\backslash \#$ shift). It is generally believed that the time delay of an onset to changes in the solar wind is on the order of 20 to $60 \mathrm{~min}$ (Gérard et al., 2004).

In the present study an investigation of the role of the time lag effect is performed to optimize the correlation for the solar wind parameters with the onset characteristics (cf. Sect. 3.4). Four different weighting functions have been applied to the propagated solar wind parameters, averaged over the three consecutive 20-min intervals of the hour prior to the respective substorm breakup. This means that the IMF parameters are expressed as averages over three 20 -min intervals $(20 \mathrm{~min}, 40 \mathrm{~min}$, and $60 \mathrm{~min}$ periods 


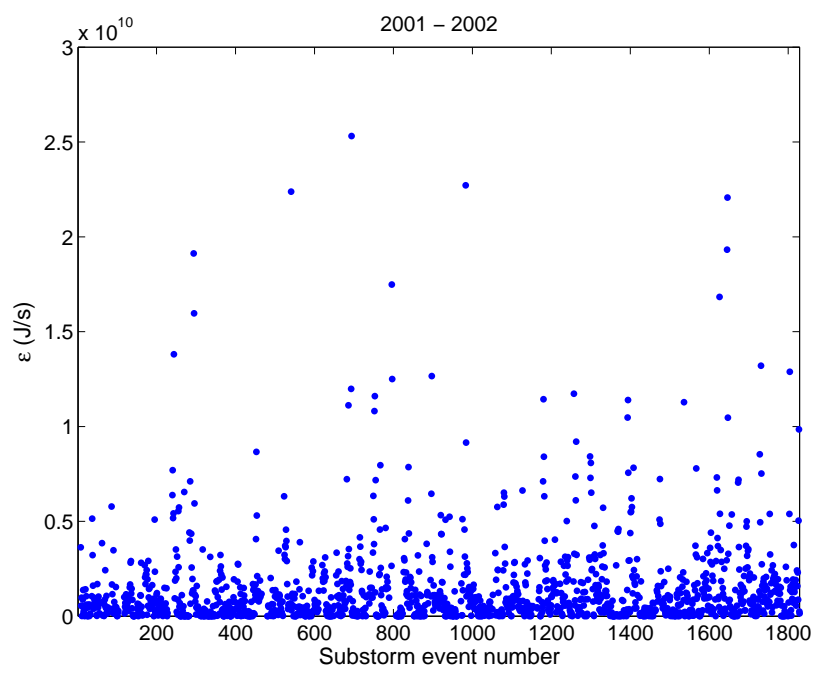

Fig. 2. Amplitudes of Akasofu coupling parameter, $\varepsilon$, for the considered substorm events.

preceding the time of the onsets observed by FUV) but weighted differently according to the models and then correlated with the substorm onset location, thereby searching for the best correlation coefficients. The four weighting functions used by Tsyganenko (2000) are the instance response function (IS) with the weights, $W_{1,2,3}=1,0,0$, the linearly increasing function (LI, mostly delayed response) with $W_{1,2,3}=0,0.5,1$, the uniform averaging function (UN), with all equal weight values $W_{1,2,3}=1,1,1$, and the linearly decreasing function (LD), with $W_{1,2,3}=1,0.5,0$, respectively. The absolute values of the weights, $W_{1,2,3}$, do not matter due to the final normalization by $\sum_{i=1}^{3} W_{i}$.

\section{Statistical results}

The large number of reported substorm events during the two years considered (1829 events) and the subset of 49 onset conjunctions with CHAMP passes are a good basis for studying the statistical properties of substorm onsets at the northern and southern poles.

\subsection{Solar wind input during substorm}

First of all, let us look at the energy input preceding the substorm events which we investigated. The period considered comprises two years (2001-2002), providing a double coverage of the seasons. The Akasofu coupling parameter, $\varepsilon$, has been shown to correlate well with the energy input during intense geomagnetic storms, as well as during individual magnetospheric substorms (Akasofu, 1979), where $\varepsilon=v_{s w}\left(B_{y}^{2}+B_{z}^{2}\right) \sin ^{4}(\theta / 2) l_{0}^{2} / \mu_{0}$, and $B_{y}, B_{z}$ are components of the interplanetary magnetic field, $v_{s w}$ is the solar wind velocity, $\theta=\tan ^{-1}\left(B_{y} / B_{z}\right)$ is the clock angle of the IMF defined in GSM coordinates, and $l_{0}$ is a constant scale length, $\simeq 7 R_{E}$. For each substorm event, averaged $\varepsilon$ parameters are calculated. The solar wind parameters at the magnetopause are averaged over 20 -min periods before the time of the onset (Gérard et al., 2004). Figure 2 shows the size of the Akasofu coupling parameter during these substorm events. It can be seen that in most cases $\varepsilon$ stays below $1 \times 10^{10} \mathrm{~J} / \mathrm{s}$, which surely indicates that the substorm events considered here are moderate, as Akasofu (1979) suggested. Intense substorms should exceed $1 \times 10^{11} \mathrm{~J} / \mathrm{s}$.

\subsection{Substorm onset position in daylight and darkness}

For the purpose of this study, all substorm onset events are sorted by the solar illumination condition during 2001 and 2002. The substorm onsets binned in magnetic latitude $\left(5^{\circ}\right)$ and local time (1-hour), are then separated into two groups, depending on the solar zenith angle (SZA). Daylight is defined as $\mathrm{SZA} \leq 100^{\circ}$ and darkness as $\mathrm{SZA} \geq 100^{\circ}$ (Wang et al., 2005). For each bin in magnetic latitude and local time an occurrence frequency was determined. The resulting maps of substorm onset distributions are shown in Fig. 3, reflecting the locations for sunlit and dark conditions. It is expected that a higher occurrence frequency of substorm onsets is observed in darkness because these events occur close to local midnight. This region is in sunlight only during the summer. There is a clear difference in local time of the substorm onset between daylight and darkness. In darkness substorm onsets tend to occur at $\sim 23: 00$ MLT, with a half-maximum width of $0.8 \mathrm{~h}$ in MLT, while in sunlight they tend to occur about an hour earlier, at $\sim 22: 00$ MLT, with a half-maximum width of $1.8 \mathrm{~h}$ in MLT. The most likely onset locations tend to occur at $66.4^{\circ}$ MLAT with half-maxima width of $4^{\circ}$ in daylight and $5^{\circ}$ in darkness. And there is also an indication for an equatorward shift in darkness, which suggests a dependence of the most probable onset latitude on the solar illumination.

\subsection{Correspondence with solar wind parameters}

It would be interesting to see whether there are interplanetary configurations favorable for triggering the substorm onset. Since a substorm is one element in a longer dynamic chain of solar wind-magnetosphere interactions, it is not obvious to expect a direct correlation of the onset with any of the solar wind parameters. Therefore, as a first step we perform a superposed epoch analysis with respect to the substorm onset time and search for systematic variations of solar wind parameters (which have been time-shifted to the dayside magnetopause). Figure 4 shows the average development of solar wind parameters, $B_{z}, E_{m}$ and $N_{p}$, one hour before and after the auroral breakup derived from this analysis. The averaged IMF $B_{z}$ attained a minimum about $20 \mathrm{~min}$ before the onset. At the time of the onset a northward turning is observed. The merging electric field, $E_{m}=v_{s w} \sqrt{B_{y}^{2}+B_{z}^{2}} \sin ^{2}(\theta / 2)$ (e.g. Kan and Lee, 1979), where $v_{s w}$ is the solar wind velocity and $\theta$ is the clock angle of the IMF defined in GSM coordinates, performs a smaller variation. The relative change $E_{m}$ is significantly less than in the case of IMF $B_{z}$. The average number density, $N_{p}$, 

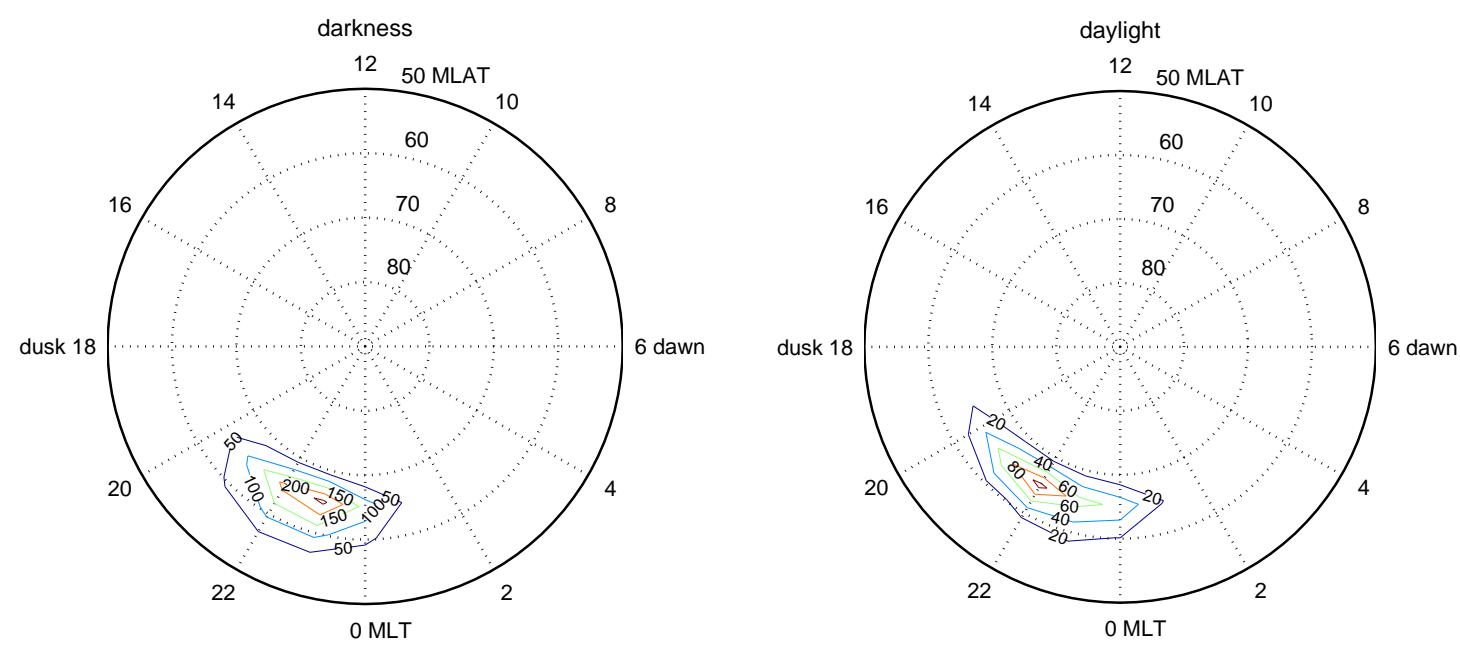

Fig. 3. Occurrence frequency of substorm onsets for daylight (left) and darkness (right).

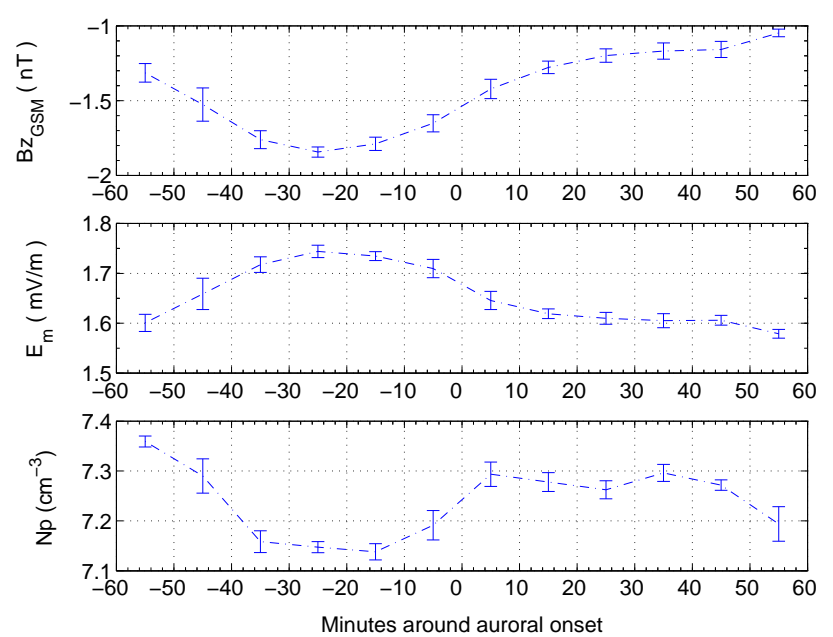

Fig. 4. Superposed epoch analysis of solar wind parameters around auroral breakup. The key time, "0", corresponds to the onset time. Parameters from top to bottom are IMF $B_{z}$, merging electric field, $E_{m}$, and solar wind density, $N_{p}$, which have been propagated to the dayside magnetopause. The bars indicate the uncertainties of the $10 \mathrm{~min}$ avearges.

also shows a decrease of about $40 \mathrm{~min}$ before the onset. The density recovers at the time of breakup. The same analysis is also performed with the other components of the IMF, the solar wind velocity, $v_{s w}$, the dynamic pressure, $P_{d y n}$, Akasofu coupling parameter, $\varepsilon$, and a more sophisticated coupling function, $\varepsilon^{\prime}=P_{d y n}^{1 / 6} v_{s w} B_{T} \sin ^{4} \varphi / 2$ (Gérard et al., 2004), where $B_{T}$ is the transverse component of the IMF and the IMF cone angle $\varphi=\tan ^{-1}\left(B_{T} / B_{x}\right)$. But none of them shows a significant signature related to the substorm onset.
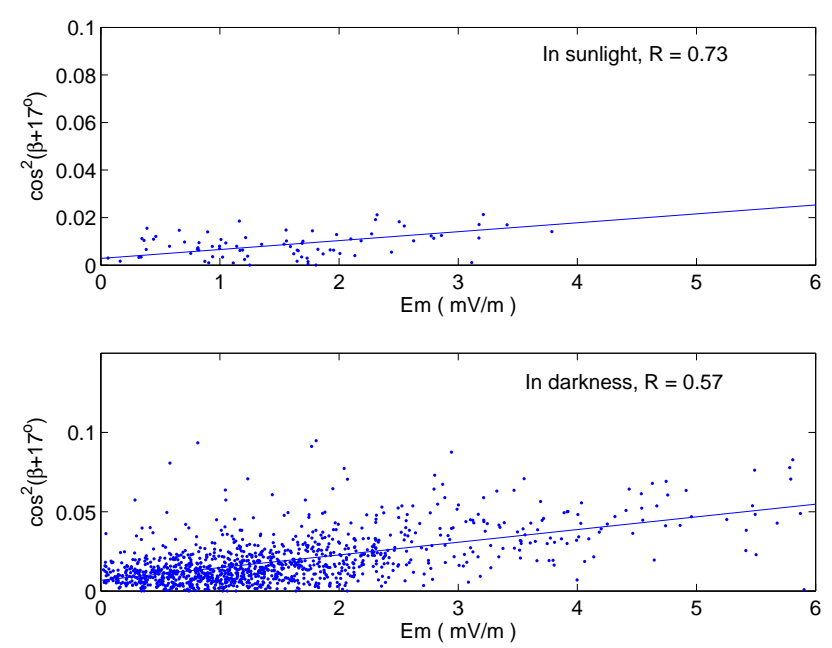

Fig. 5. Correlation between merging electric field $\left(E_{m}\right)$ and increase in polar cap area $\alpha \cos ^{2}(\beta+\delta)$, where $\beta$ is the geomagnetic latitude of the substorm onset $\left(\delta=17^{\circ}\right.$, see text).

\subsection{Correlation of the onset latitude with solar wind param- eters}

In a next step we are interested in finding a relation between the solar wind input and the latitude of the substorm onset. During the growth phase magnetic flux is added to the magnetotail. This causes the polar cap to expand. Since the area of the polar cap and accordingly the amount of magnetic flux in the tail lobes increase proportional to the square of the polar cap radius (Kivelson and Russell, 1994) (cf. Sect. 9.3), we assume a parabolic relation between the solar wind input and the latitude of the substorm. 


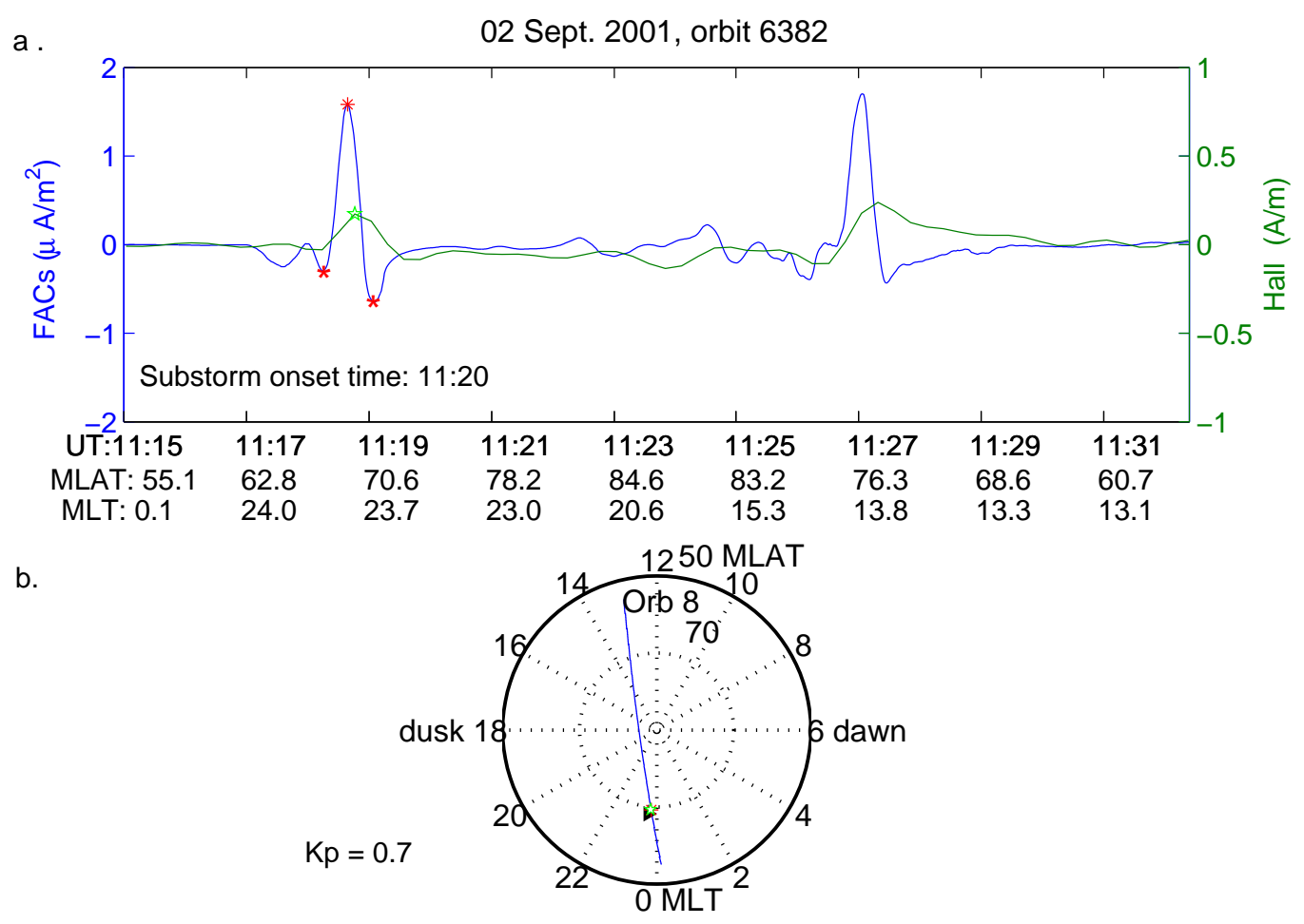

Fig. 6. (a) Ionospheric currents observed by CHAMP at the time of the auroral breakup event shown in Fig. 1. Positive FACs are directed upward, positive Hall currents flow westward on the nightside and eastward on the dayside. As shown in the lower plot (b), the substorm onset location coincides well with the peaks in FAC and Hall currents.

Figure 5 shows the relationship between the merging electric field and the magnetic latitude, $\beta$, of the substorm onset separately for sunlit and dark conditions. We employed the merging electric field, $E_{m}$, as the suitable geoeffective solar wind coupling parameter for loading the magnetosphere, as shown above and following the results derived by Wang et al. (2005). A linear correlation is performed between the merging electric field and a quadratic function for the polar cap area $\left(\cos ^{2}(\beta+\delta)\right)$. The angular width, $\delta$, of the polar cap at quiet times has been determined by testing different values. The angle $\delta=17^{\circ}$ gave the best correlation results. The cross polar cap potential tends to saturate at very high activity (Nagatsuma, 2004). Therefore, the correlation has been limited to $E_{m} \leq 6 \mathrm{mV} / \mathrm{m}$ in our study. With this selection we avoid non-linear responses and saturation of the system at extreme activity, which may complicate the interpretation. For the correlation with $\cos ^{2}(\beta+\delta)$ the optimal weighting for $E_{m}$ turned out to be the uniform functions (UN) with the correlation coefficient $R=0.5897$. For IS, LI, LD functions the correlation coefficients are $0.5535,0.5708$ and 0.5864 , respectively. From the regression line fit in Fig. 5 we obtain the relation for the onset latitudes. In sunlight we obtain $\beta=73^{\circ}-2.6 \sqrt{E_{m}}$ and in darkness $\beta=73^{\circ}-5.2 \sqrt{E_{m}}$, where $E_{m}$ is measured in $\mathrm{mV} / \mathrm{m}$. This suggests that the latitudinal response to the solar wind input is significantly stronger during the dark seasons.
3.5 Correspondence between substorm onset, field-aligned currents, and Hall currents

For this comparison 49 CHAMP orbits with close approaches to the events are selected in the Northern and Southern Hemispheres for the years 2001 and 2002. These passes are used to study additional features (e.g. FAC signatures and Hall currents) of the substorm onsets. As an example, Fig. 6 shows the FAC and Hall current intensities for one CHAMP pass (orbit 6382) during a period of low geomagnetic activity on 2 September 2001. The average Kp for this event is 0.7 and the $D_{s t}$ value is about $-4 \mathrm{nT}$. The onset occurs at 11:20 UT, 68.13 ${ }^{\circ}$ MLAT and 23.61 MLT (cf. Fig. 1).

In Fig. 6a, the peak upward FAC and two flanking downward FACs are marked by asterisks, and the peak Hall current density by a pentacle. In Fig. $6 \mathrm{~b}$ the reported substorm onset position is shown as a triangle and the peak upward FAC is marked by an asterisk, and the peak Hall current density by a pentacle. We see the well-known three-sheet FAC structure, which is typical for the Harang discontinuity. There is an upward FAC in the middle, flanked by two downward FACs, both poleward and equatorward, which seems to be an onsetrelated feature (Papitashvili et al., 2002). From Fig. 6a, it can be seen that the positive Hall current peak indeed occurs during the ascending phase of this CHAMP orbit. The positive Hall current peak, therefore, corresponds to a westward Hall 

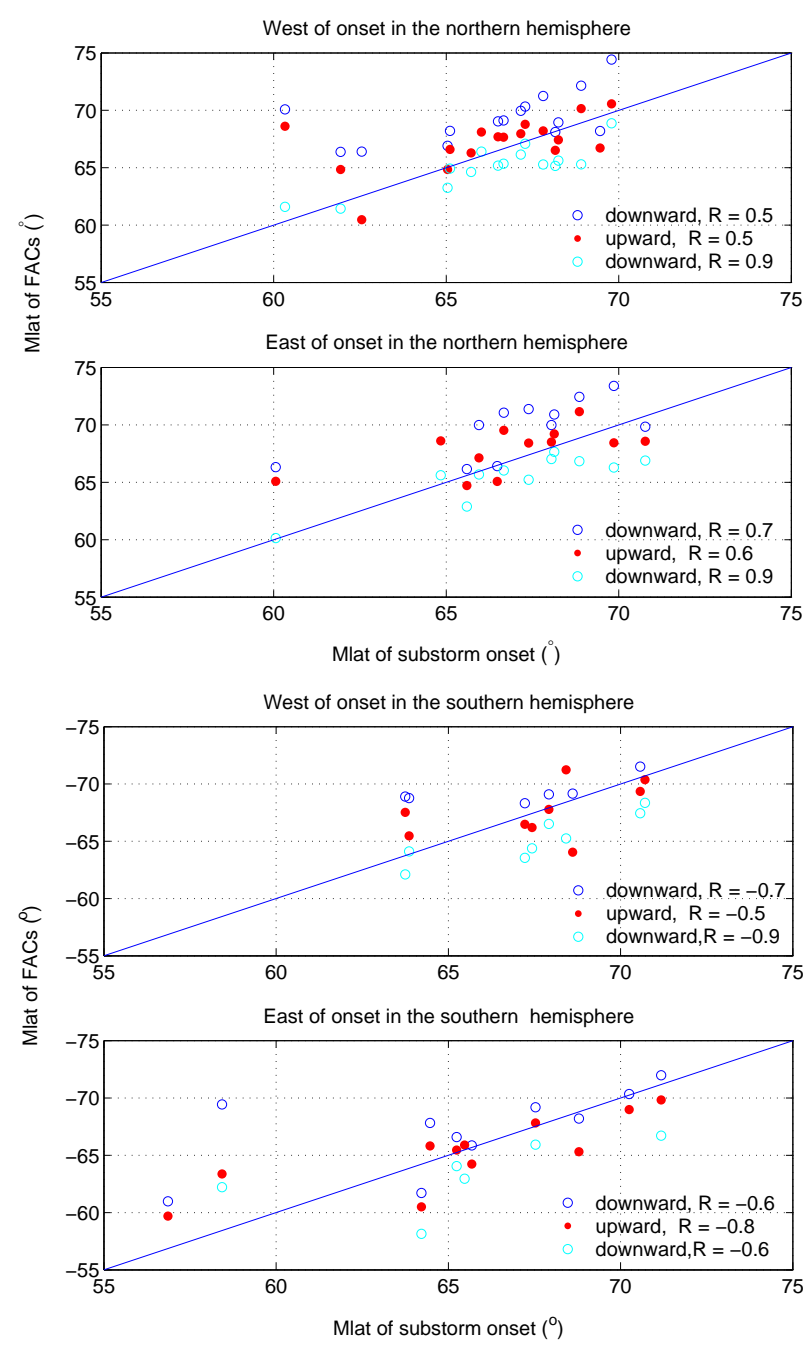

Fig. 7. Relationship between the reported onset latitude and the observed latitude of each of the three-sheet FAC currents in the auroral oval in the Northern (top) and Southern Hemisphere (bottom), separated for CHAMP passes to the west or east of the onset location.

current. This weak westward Hall current of about $0.2 \mathrm{~A} / \mathrm{m}$ exists poleward of the central FAC at this substorm onset. CHAMP passes on the east side close to the onset region $(0.08 \mathrm{~h}$ in MLT) shortly before the detection of the substorm onset (about $1 \mathrm{~min}$ ) (cf. Fig. 6b).

The two or three main FAC sheets, the peak Hall current and the substorm onset location are selected in the same way for all 49 events. Sometimes there are only two sheets in the vicinity of the substorm onsets, which could be related to the selection criterion that sheets with peak densities less than $0.02 \mu \mathrm{A} / \mathrm{m}$ are omitted (Wang et al., 2005). The relationship between the reported onset latitudes, the two or three field-aligned current sheets and peak Hall currents in both hemispheres are shown in Figs. 7 and 8. All events are separated into two subsets according to (1) all passes west of the onset (upper panel) and (2) all passes east of the onset (lower panel), separately for both hemispheres. Upward
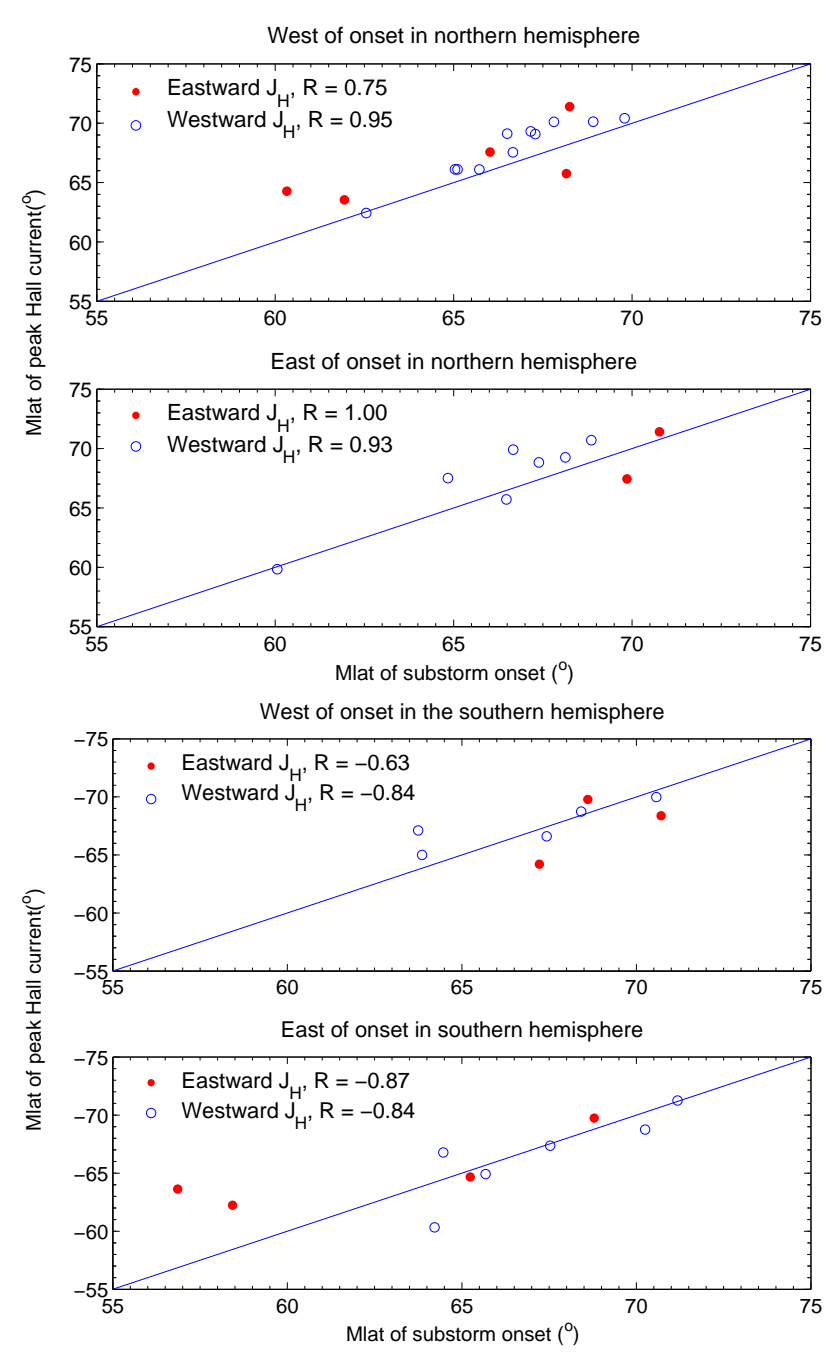

Fig. 8. Same presentation as Fig. 7, but for the relationship between the onset latitude and the latitude of the peak Hall current in the auroral oval.

and downward FACs, as well as eastward and westward Hall currents, are displayed as solid dots and open circles, respectively. Poleward and equatorward downward FACs are colored differently. In the Northern Hemisphere there are 17(12) events where CHAMP passed on the west(east) side of the onset location and in the Southern Hemisphere there are 9(11) events of west(east) passes.

In Fig. 7, it can be seen that there is a good correlation between the latitudes of upward and downward FACs and substorm onsets with correlation coefficients $(R)$ no less than 0.5 . As expected, the upward FACs center closest to the onset location and the two flanking downward FACs on average locate poleward and equatorward of the onset. There is a little scattering of the upward FACs about the center line, which means that the upward FACs are not exactly collocated with the reported auroral precipitation. There are no significant differences between events west and east of the onset. The upward and downward FAC locations in the Southern 
Hemisphere are found to deviate more from the center line than in the Northern Hemisphere. This may be due to the fact that the substorm onset is detected in the Northern Hemisphere and mapped to the conjugate point, while the currents are measured directly in the Southern Hemisphere. Reliable observations of substorm onset in the Southern Hemisphere will be required to complete the global picture.

The behavior of the Hall currents is shown in Fig. 8. Events with quite small Hall current densities (below noise level of $0.04 \mathrm{~A} / \mathrm{m}$ ) are omitted (Ritter et al., 2004). In the Northern Hemisphere, it can be seen that westward Hall currents dominate in the majority of the cases (18:7). The westward Hall current is encountered about $2^{\circ}$ poleward of the reported onset. In the conjugate Southern Hemisphere, it can be seen that the westward Hall currents dominate (11:7). They scatter a little more around the central line. From Figs. 7 and 8 we can see that in the Northern Hemisphere the upward detected currents are closest to the reported onsets and Hall currents are about $2^{\circ}$ poleward of the reported onsets. Larger deviations occur during intense events.

\section{Discussion}

In this study we have investigated certain features of substorm onsets by combining observations from the ACE, IMAGE and CHAMP satellites. Some interesting results about the onset locations and associated ionospheric currents are obtained.

\subsection{Latitude dependence on solar illumination}

The distribution in MLT and MLAT of the substorm onsets observed between 2001 and 2002 with the most probable onset location at 22:23 MLT and $66.43^{\circ}$ MLAT confirms previous findings (e.g. Liou et al., 2001). The large amount of substorm events are evenly distributed in magnetic longitudes without any bias (Frey et al., 2004). Only 8 onsets (0.4\%) were observed to initiate at very early mangetic local times (near 19:00 MLT). This is consistent with DE 1 (Craven and Frank, 1991) and Viking observations (Henderson and Murphree, 1995).

The most probable onset location in daylight is 22:00 MLT and in darkness, 23:00 MLT. This result is compatible with the conclusions of a seasonal study by Liou et al. (2001), who found onset locations centered around 21:30 MLT in summer and 23:00 MLT in winter, using POLAR observations. The authors suggested that the IMF $B_{y}$ component affects the shift of onset in MLT. Onset locations should shift toward earlier local times for $B_{y}>0$ and to later times for $B_{y}<0$ (Liou et al., 2001). Under this aspect, positive $B_{y}$ should dominate in our statistics in daylight and negative $B_{y}$ in darkness. But after we sum up all events with positive versus negative $B_{y}$ in sunlight and in darkness, we found 246:262 in sunlight and 827:674 in darkness, which gives just the opposite ratio than the above suggestion. Furthermore, we found no correlation between $B_{y}$ and MLT.
The correlation coefficient for the different delay models amounts to $R=-0.083$ (IS), $-0.082(\mathrm{LI}),-0.092$ (UN) and $-0.095(\mathrm{LD})$. Therefore, we may claim that the determined local time shift is caused by other factors, possibly influenced by the solar illumination.

From Fig. 3 one can also see that there is an indication for an equatorward shift of the substorm onset in darkness. We have performed a more detailed examination. We binned substorm onsets in magnetic latitude $\left(0.5^{\circ}\right)$, and then separated them into two groups according to daylight and darkness. The occurrence frequency was determined for each MLAT bin. It was found that in sunlight the most probable onset latitude was about $67^{\circ}$ and in darkness $65.5^{\circ}$. This result is consistent with earlier findings that the solar illumination can influence the position of the auroral oval. In the pre-midnight sector, the auroral oval expands in the case of darkness by about $1.5^{\circ}$ equatorward (Wang et al., 2005). The onset location was found by Gerard et al. (2004) to occur at a fixed distance to the equatorward boundary of the auroral oval. Both features are obviously shifted poleward in sunlight. Based on this study we cannot make a firm conclusion on the effect this may have on the source region in the tail.

\subsection{Latitude dependence on solar coupling parameters}

The substorm initial phase may be closely related to a preceeding southward IMF, thus suggesting that magnetic reconnection is much more important for substorms than the viscous interaction (Cowley, 1982). Kamide et al. (1977) also showed that the probability of the substorm occurrence increases with the growing strength of the southward IMF. Our superposed epoch analysis (cf. Fig. 4) shows that the average IMF $B_{z}$ was southward prior to the onset, suggesting an enhanced energy input from the solar wind into the magnetosphere. As a consequence, the cross-tail current may increase, finally producing a substorm (Akasofu, 2004). Our analysis shows that substorms occur during a positive turning of the IMF $B_{z}$. It has been demonstrated that a northward turning of IMF can trigger substorms (Lyons, 1996). The cross-tail current may increase during a period of southward IMF. A reduction in negative $B_{z}$ may cause a sudden decrease of the tail current and thus can trigger a substorm (Akasofu, 2004). Therefore, the northward turning seems to be a subset of the substorm onset process. There is also a sudden increase in solar wind density at the key time (cf. Fig. 4), however, the change is rather small, $2 \%$, which may not be enough for a significant influence. Other coupling parameters, such as the dynamic pressure or the Akasofu parameter, revealed no dependence. This should be considered in substorm onset models.

The effect of the solar wind input on the onset latitude is in agreement with earlier conclusions. For more positive $E_{m}$ we find the more equatorward location of the onsets, which indicates increasing magnetic flux in the magnetotail. The obtained correlation coefficients are $R=0.57$ and 0.73 for darkness and daylight, respectively. The onset latitudes respond differently to the merging electric field, $E_{m}$, for sunlight or 
darkness. The degree of equatorward expansion of the substorm onset responds stronger to $E_{m}$ in darkness than in daylight, which clearly supports our earlier result that the substorm onsets tend to occur on average more equatorward in darkness than in sunlight.

The best weighting function we found in this study for $E_{m}$ and onset latitude is the uniform function, which averages the solar wind data evenly over one hour before the substorm onset. This may imply that integrating the solar wind input at the magnetopause over the preceeding $60 \mathrm{~min}$ is suitable to charaterize the processes in the middle and distant tail of the magnetosphere before the substorm.

\subsection{Relation between onset location and FACs and Hall current latitudes}

Our results (cf. Fig. 7) show clearly that the substorm onset location correlates well with the most prominent fieldaligned currents and Hall currents in that region. Fieldaligned currents, especially upward FACs, are considered to carry most of the energetic electrons. Therefore, it is natural to expect that these field-aligned currents and auroral images display coherent variations during a substorm. In our study a little scatter of the upward FACs about the center line can be found (cf. Fig. 7), which means that the upward FACs are not exactly collocate with the reported auroral precipitation. Lu et al. (1997) also found that the brightest aurora in the central auroral oval tends to reside at the boundary between upward and downward currents. They attributed this to the inability of the AMIE technique to capture the fine structure of FACs associated with discrete auroras. Our data processing with the high-pass filtering at the 20-s cutoff period, also suppress the intense small-scale FACs (Wang et al., 2005).

It is usually thought that the auroral electrojets are most intense in the region of bright auroral luminosity because the precipitating energetic particles enhance the ionospheric conductivity (Kamide and Kokubun, 1996). However, the reality is more complicated than this simple view suggests, because there are differences and partly because there are overlaps of the electrojet peaks and peaks in auroral luminosity as a result of the combined roles of the ionospheric electric fields and conductivities, as suggested by Kamide and Kokubun (1996). They claim that there are two kinds of electrojet currents: one is related to the convection electric field, giving eastward currents on the dusk side and westward ones on the dawn side, and the other is related to the conductivity enhancement, supporting a westward current around the midnight sector. These two types of currents coexist in the Harang discontinuity and their relative strength varies with time, making the interpretation of individual current patterns very complicated.

Our results show that the westward auroral electrojets dominate in the pre-midnight sector (cf. Fig. 8). They tend to reside about $2^{\circ}$ in latitude poleward of the substorm onset. This is consistent with the classic pictures of a westward travelling surge (WTS). Ground-based observations of a WTS show westward ionospheric currents in the north and weaker eastward currents in the south, furthermore southward currents west of the surge (Lühr et al., 1998). According to the WTS model of Kirkwood et al. (1988), the bright auroral feature in the surge is connected to a strong upward FAC. Behind the surge (to the east) there is a channel of very high conductance. Lewis et al. (1997) suggested that the dominant upward FAC in the WTS is connected to the substorm current wedge (SCW). In the Northern Hemisphere this FAC drives a counterclockwise ionospheric Hall current flowing around it shortly after the substorm onset. Prominent eastward auroral electrojets are more evenly distributed about the central line (cf. Fig. 8). Some of them can also be found poleward of the prominent downward FACs. In accordance with that, Kamide and Kokubun (1996) found that the upward fieldaligned current distribution during the substorm expansion phase sometimes has multiple peaks, which are related either to the convection electrojet or to the substorm-expansion jets.

An important result of this study is that the average location of substorm onset differs for sunlit and dark ionospheres, in both local time and latitude. In this context, there should be a systematic displacement in the onset position in both hemispheres, since we have a sunlit polar region in the Northern Hemisphere during summer solstice and at the same time darkness in the south. We cannot test this conclusion because we do not have simultaneous observations in the Southern Hemisphere. A previous study argued that the MLT differences of onset locations in the two hemispheres were caused by the magnetic tension force acting on open magnetic field lines, which was due to the IMF $B_{y}$ effect (Østgaard et al., 2004). Their results were based on 5 substorm onset observations in both hemispheres. However, in our study, we find little effect of the IMF $B_{y}$ on the onset location (cf. Sect. 4.1). There were also other explanations about the dissymmetrical latitude and longitude of the auroral breakups in the northern and southern hemispheres, such as the magnetospheric currents or IMF influence on the magnetospheric field configuration (e.g. Burns et al., 1997; Stenbaek-Nielsen and Otto, 1997). Here we suggest that the solar illumination may also have an important effect on the nonconjugated location of the onsets in both hemispheres. There is feedback regarding the sunlit ionosphere on the auroral electrodynamics. The energetic electrons causing the auroral features are accelerated in a region only some thousand kilometers above the Earth. These acceleration regions probably work independently in the two hemispheres. The feedback of the ionospheric conductivity on the acceleration of precipitating electrons has been shown by Newell et al. (1996). This effect causes a suppression of discrete auroras in sunlight. We think that the preexisting ionospheric conductivity has an influence on the location of the auroral acceleration region, possibly by moving to a latitude favorable for the instability, which is thought to be an element of the acceleration process (Haerendel, 1990). Sato et al. (1998) reported that ionospheric conductivity might explain why auroral features sometimes occur in one hemisphere and are absent in the other hemisphere. When accepting this concept it is no surprise that the observed FACs and electrojets in 
the Southern Hemisphere may deviate significantly from the conjugate point of the substorm onsets in the Northern Hemisphere due to differences in illumination conditions. For verify that statement a sufficiently large number of substorm onsets at conjugate sites is required.

\section{Summary and conclusions}

The statistical analysis of a larger number of substorm onset characteristics, by combining observations from the satellites ACE, IMAGE and CHAMP, has revealed several interesting features. Solar illumination and with it the ionospheric conductivity have a significant effect on the most probable substorm onset latitude and local time. In sunlight, substorm onsets tend to occur at about $1 \mathrm{~h}$ earlier in local time and $1.5^{\circ}$ more poleward than in darkness. The solar wind input, here represented by the merging electric field, integrated over one hour prior to the substorm, correlates well with the latitude of the breakup. The most poleward latitudes of the onsets are found to range around $73^{\circ}$ MLAT during very quiet times. Concurrently, the observed field-aligned and Hall currents are consistent with the notion of a westward travelling surge evolving out of the Harang discontinuity. Based on the observed difference in onset location between events in sunlight and darkness we suggest that the formation of the auroral acceleration region occurs independently in both hemispheres and is influenced by the ionospheric conductivity. As a consequence of this, the mapping of the onset location into the tail might become even more uncertain.

Acknowledgements. We are obliged to H. Frey for making the list of auroral substorm onsets obtained by IMAGE-FUV and Fig. 1 available to us. We thank F. Christiansen for providing the ACE IMF data propagated to the magnetopause. We thank the ACE MAG and SWEPAM instrument teams and the ACE Science Center for providing the ACE data. The Deutsche Akademische Austauschdienst (DAAD) supported HW through the Sandwich-type scholarship programme between China and Germany. This study is also supported by the China Ministry of Science and Technology (No. G2000078407) and National Nature Science Foundation of China (No. 40390150). The operational support of the CHAMP mission by the German Aerospace Center (DLR) and the financial support for the data processing by the Federal Ministry of Education (BMBF), as part of the Geotechnology Programme, are gratefully acknowledged.

Topical Editor M. Pinrock thanks two referees for their help in evaluating this paper.

\section{References}

Akasofu, S. I.: The development of the auroral substorms, Planet. Space. Sci., 12, 273-282, 1964.

Akasofu, S. I.: Interplanetary energy flux associated with magnetospheric substorms, Planet. Space. Sci., 27, 425-431, 1979.

Akasofu, S. I.: Several 'Controversial' Issues on Substorms, Space Science Review, 113, 1-40, 2004.

Baker, D. N., Pulkkinen, T. I., Angelopoulos, V., Baumjohann, W., and McPherron, R. L.: Neutral line model of substorms: Past results and present view, J. Geophys. Res., 101, 12 975-13010, 1996.

Burns, G. B., McEwen, D. J., Eather, R. A., Berkey, F. T., and Murphree, J. S.: Optical auroral conjugacy: Viking UV imager-South Pole station ground data, J. Geophys. Res., 95, 5781-5790, 1997.

Cowley, S. W. H.: The cause of convection in the Earth's magnetosphere: A review of developments during the IMS, Rev. Geophys., 20, 531-565, 1982.

Craven, J. D. and Frank, L. A.: Diagnosis of auroral dynamics using global auroral imaging with emphasis on large-scale evolutions, in: Auroral Physics, edited by: Meng, C. I., Rycroft, M. J., and Frank, L. A., Cambridge Univ. Press, New York, 273-288, 1991.

Frey, H. U., Mende, S. B., Angelopoulos, V., and Donovan, E. F.: Substorm onset observations by IMAGE-FUV, J. Geophys. Res., 109, doi:10.1029/2004JA010607, 2004.

Gérard, J. C., Hubert, B., Grard, A., and Meurant, M.: Solar wind control of auroral substorm onset location observed with the IMAGE-FUV imagers, J. Geophys. Res., 109, A03208, doi:10.1029/2003JA010129, 2004.

Haerendel, G.: Field-aligned currents in the earth's magnetosphere, in: Physics of Magnetic Flux Ropes, edited by: Russell, C. T., Priest, E. R., and Lee, L. C., AGU Press, Washington D.C., 539553, 1990.

Henderson, R. H. and Murphree, J. S.: Comparison of Viking onset locations with the predictions of the thermal catastrophe model, J. Geophys. Res., 100, 21 857-21 872, 1995.

Kamide, Y. and Kokubun, S.: Two-component auroral electrojet: Importance for substorm studies, J. Geophys. Res., 101, 13027$13046,1996$.

Kamide, Y., Perreault, P. D., Akasofu, S. I., and Winningham, J. D.: Dependence of substorm occurrence probability on the interplanetary magnetic field and on the size of the auroral oval, J. Geophys. Res., 82, 5521-5528, 1977.

Kan, J. R. and Lee, L. C.: Energy coupling function and solar windmagnetosphere dynamo, Geophys. Res. Lett., 6, 577-580, 1979.

Kirkwood, S., Opgenoorth, H. J., and Murphree, J. S.: Ionospheric conductivities, electric fields and currents associated with auroral substorms measured by the EISCAT radar, Planet. Space. Sci., 36, 1359-1380, 1988.

Kivelson, M. G. and Russell, C. T.: Introduction to Space Physics, Cambridge U. Press, 1994.

Koskinen, H. E. J. and Pulkkinen, T.: Midnight velocity shear zone and the concept of Harang discontinuity, J. Geophys. Res., 100, 9539-9547, 1995.

Lühr, H., Aylward, A., Bucher, S. C., Pajunpää, A., Pajunpää, K., Holmboe, T., and Zalewski, S. M.: Westward moving dynamic substorm features observed with the IMAGE magnetometer network and other ground-based instruments, Ann. Geophys., 16, 425-440, 1998,

SRef-ID: 1432-0576/ag/1998-16-425.

Lewis, R. V., Freeman, M. P., Rodger, A. S., Reeves, G. D., and Milling, D. K.: The electric field response to the growth phase and expansion phase onset of a small isolated substorm, J. Geophys. Res., 15, 289-299, 1997.

Liou, K., Meng, C. I., Lui, T. Y., Newell, P. T., Brittnacher, M., Parks, G., Reeves, G. D., Anderson, R. R., and Kumoto, K.: On relative timing in substorm onset signatures, J. Geophys. Res., 104, doi:10.1029/1999JA900206, 1999.

Liou, K., Newell, P. T., Sibeck, D. G., and Meng, C. I.: Observation of IMF and seasonal effects in the locaiton of auroral substorm onset, J. Geophys. Res., 106, 5799-5810, 2001.

Liou, K., Meng, C. I., Lui, A. T. Y., Newell, P. T., and Wing, S.: 
Magnetic dipolarization with substorm expansion onset, J. Geophys. Res., 107, 1131, 2002.

Lu, G., Siscoe, G. L., Richmond, A. D., Pulkkinen, T. I., Tsyganenko, N. A., Singer, H. J., and Emery, B. A.: Mapping of the ionospheric field-aligned currents to the equatorial magnetosphere, J. Geophys. Res., 102, 14 467-14 476, 1997.

Lui, A. T. Y.: Current disruption in the Earth's magnetosphere: Observations and models, J. Geophys. Res., 101, 13 067-13088, 1996.

Lyons, L. R.: Substorms: Fundamental observational features, distinction from other disturbances, and external triggering, J. Geophys. Res., 101, 13011-13 026, 1996.

Mende, S. B., Carlson, C. W., Frey, H. U., Peticolas, L. M., and Østgaard, N.: FAST and IMAGE-FUV observations of a substorm onset, J. Geophys. Res., 108, A91344, doi:10.1029/2002JA009787, 2003.

Nagai, T., Fujimoto, M., Saito, Y., Machida, S., Terasawa, T., R. Nakamura, T. Y., Mukai, T., Nishida, A., and Kokubun, S.: Structure and dynamics of magnetic reconnection for substorm onsets with Geotail observations, J. Geophys. Res., 103, 44194440, 1998.

Nagatsuma, T.: Conductivity dependence of cross-polar potential saturation, J. Geophys. Res., 109, doi:10.1029/2003JA010286, 2004.

Newell, P. T., Meng, C. I., and Lyons, K. M.: Suppression of discrete aurora by sunlight, Nature, 38, 766-767, 1996.

Østgaard, N., Mende, S. B., Frey, H. U., Immel, T. J., Frank, L. A., and Sigwarth, J. B.: Interplanetary magnetic field control of the location of substorm onset and auroral features in the conjugate hemispheres, J. Geophys. Res., 109, doi: 10.1029/2003JA010370, 2004.

Papitashvili, V. O., Clauer, C. R., Christiansen, F., Kamide, Y., Petrov, V. G., Rasmussen, O., and Watermann, J. F.: NearConjugate Magnetic Substorms at Very High Latitudes Observed by Greenland and Antarctic Ground Magnetometers and Ørsted Satellite, in: Sixth International Conference on Substorms edited by: Winglee, R. M., University of Washington, Seattle, 110-114, 2002.
Reigber, C., Lühr, H., and Schwintzer, P.: CHAMP mission status, Adv. Space Res., 30, 129-134, 2002.

Richmond, A. D.: Ionospheric Electrodynamics Using Magnetic Apex Coordinates, J. Geomagn. Geoelectr., 47, 191-212, 1995.

Ritter, P., Lühr, H., Viljanen, A., Amm, O., Pulkkinen, A., and Sillanpää, I.: Ionospheric currents estimated simultaneously from CHAMP satellite and IMAGE ground-based magnetic field measurements: A statistical study at auroral latitudes, Ann. Geophys., 22, 417-430, 2004,

SRef-ID: 1432-0576/ag/2004-22-417.

Rostoker, G., Akasofu, S.-I., Baumjohann, W., Kamide, Y., and McPherron, R. L.: The roles of direct input of energy from the solar wind and unloading of stored magnetotail energy in driving magnetospheric substorms, Space Science Review, 46, 93-111, 1987.

Sato, N., Nagaoka, T., Hashimoto, K., and Saemundsson, T.: Conjugacy of isolated auroral arcs and nonconjugate auroral breakups, J. Geophys. Res., 103, 11 641-11 652, 1998.

Shiokawa, K., Baumjohann, W., Haerendel, G., Paschmann, G., Fennell, J. F., Friis-Christensen, E., Lühr, H., Reeves, G. D., Russel, C. T., Sutcliffe, P. R., and Takahashi, K.: High-speed ion flow, substrom current wedge, and multiple Pi2 pulsations, J. Geophys. Res., 103, 4491-4507, 1998.

Stenbaek-Nielsen, H. C. and Otto, A.: Conjugate auroras and the interplanetary magnetic field, J. Geophys. Res., 102, 2223-2232, 1997.

Tsyganenko, N. A.: Solar wind control of the tail lobe magnetic field as deduced from Geotail, AMPTE/IRM, and ISEE 2 data, J. Geophys. Res., 105, 5517-5528, 2000.

Wang, H., Lühr, H., and Ma, S. Y.: Solar zenith angle and merging electric field control of field-aligned currents: A statistical study of the Southern Hemisphere, J. Geophys. Res., 110, doi:10.1029/2004JA010530, 2005. 